\title{
Serum Neuron Specific Enolase and S-100B Levels in Hemodialysis and Peritoneal Dialysis Patients
}

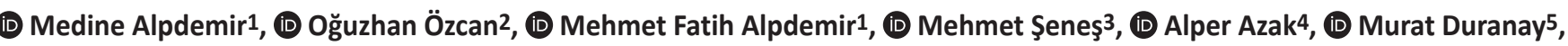 \\ (D) Doğan Yücel3
}

${ }_{1}^{1}$ Balıkesir State Hospital, Biochemistry, Balıkesir, Turkey

${ }^{2}$ Hatay Mustafa Kemal University Faculty of Medicine, Department of Medical Biochemistry, Hatay, Turkey

${ }^{3}$ Ankara Training and Research Hospital, Department of Biochemistry, Ankara, Turkey

${ }^{4}$ Balıkesir State Hospital, Nephrology, Balıkesir, Turkey

${ }^{5}$ Ankara Training and Research Hospital, Department of Nephrology, Ankara, Turkey

\section{Abstract}

Objective: Neuron-specific enolase (NSE) and S-100B are brain-derived proteins, and their levels increase in brain injury. The aim of the study was to determine serum S-100B and NSE levels in patients with end-stage renal disease undergoing hemodialysis (HD) and peritoneal dialysis (PD) and to demonsrate how these levels were affected by the type of dialysis applied.

Methods: The study group consisted of age- and gender-matched 20 patients undergoing HD, 26 patients undergoing continuous ambulatory PD (CAPD) and 21 healthy controls. Blood samples were obtained before and after dialysis in the HD patient group, and fasting blood samples were obtained in the CAPD and control groups. The routine biochemical parameters were measured within two hours from all serum samples. The remaining serum samples were stored at $-80{ }^{\circ} \mathrm{C}$ until the day of analysis of the S-100B and NSE assays. Serum S-100B and NSE levels were measured by chemiluminescence immunoassay method. Routine biochemistry tests were measured by colorimetric method using a biochemistry analyzer.

Results: Serum S-100B $(0.11 \pm 0.06 \mathrm{ng} / \mathrm{mL}$ in HD, $0.13 \pm 0.09 \mathrm{ng} / \mathrm{mL}$ in CAPD and $0.05 \pm 0.03 \mathrm{ng} / \mathrm{mL}$ in controls) and NSE (12.7 $\pm 5.99 \mathrm{ng} / \mathrm{mL}$ in $\mathrm{HD}$, $9.26 \pm 5.52 \mathrm{ng} / \mathrm{mL}$ in CAPD and $6.82 \pm 2.36 \mathrm{ng} / \mathrm{mL}$ in controls) levels were higher in HD and CAPD groups compared to controls. S-100B and NSE levels were higher after HD compared to before HD $(p<0.001)$. There was a weak but significant correlation between S-100B and NSE levels $(r=0.290$; $\mathrm{p}=0.006)$.

Conclusion: In this study, serum S-100B and NSE levels were found to be high in patients undergoing HD and PD. Serum S-100B and NSE concentrations were higher in HD and CAPD patients. Increased S-100B and NSE levels may be associated with cerebrovascular events in patients with chronic renal failure. They may also be important markers for the determination of cerebrovascular events.

Keywords: Brain damage, end stage renal failure, hemodialysis, neuron-specific enolase, peritoneal dialysis, S-100B

\section{INTRODUCTION}

Neuron-specific enolase (NSE) and S-100B are specific brainderived proteins that have recently gained importance as neurochemical markers (1). Serum concentrations of these analytes increase after traumatic brain injury and clinical conditions that result in brain injury, such as cardiac arrest and cardiopulmonary bypass surgery $(2,3)$. S-100B is a calcium- binding protein, approximately $21 \mathrm{kDa}$ in weight and composed of subunits A and B. Subunit B is synthesized mainly by astroglial and microglial cells and is highly specific for the central neurological system $(4,5)$. The half-life of S-100B in the serum is reported to be approximately two hours, and it is metabolized and excreted by the kidneys. Its concentrations are normally undetectable in serum samples, but can reach measurable levels 
following certain clinical conditions such as stroke, subarachnoid hemorrhage, head trauma, and extracorporeal circulation (6-8).

NSE is a dimeric isoenzyme of the glycolytic enzyme enolase that is approximately $78 \mathrm{kDa}$ in weight and has a biological half-life of about 24 hours. It is highly localized in neurons and neuroendocrine cells, and constitutes $1.5 \%$ of soluble proteins in brain tissue (9). When brain tissues are injured, NSE diffuse into cerebrospinal fluid (CSF) and systemic circulation $(1,10)$. Recent studies have suggested that increased NSE concentrations in serum and CSF can be used as a sensitive and quantitative marker for parenchymal damage in brain tissue, cerebral infarction and intracerebral hemorrhage $(9,11)$.

Chronic renal disease is defined as an irreversible and progressive decrease $\left(<60 \mathrm{~mL} / \mathrm{min} / 1.73 \mathrm{~m}^{2}\right)$ in the glomerular filtration rate (GFR). When chronic and progressive deterioration reaches an advanced stage, it is called chronic renal failure (CRF). CRF is associated with severe disorders in the fluid and electrolytes balance, as well as in metabolic-endocrine functions. It is well known that decreased GFR is a risk factor for cerebrovascular and cardiovascular diseases. Cerebrovascular diseases are considered as one of the most important causes of higher morbidity and mortality in patients with end-stage renal disease (ESRD). It has been reported that there is a relationship between ESRD and several cerebral pathologies, including stroke, cerebral microvascular disease, silent lacunar infarct, white matter lesions and cerebral microvascular hemorrhages (12).

Controlling these risk factors plays a key role in the prevention of cerebral diseases and improving the quality of life of patients with ESRD. Magnetic resonance imaging (MRI) is still the most valuable diagnostic tool and is commonly used in the diagnosis of cerebrovascular diseases in these patients. As neurochemical markers, serum S-100B and NSE can be useful for early diagnosis of brain damage.

The purpose of this study was to determine serum NSE and S-100B levels in patients undergoing hemodialysis (HD) and continuous ambulatory peritoneal dialysis (CAPD), to compare these values with the control group, and to assess these neurochemical markers before and after a single HD session.

\section{METHODS}

\section{Subjects}

Twenty patients who underwent HD and 26 patients who underwent CAPD were included in the study. Twenty-one age- and gender-matched healthy controls without any systemic disease such as hypertension, chronic renal disease, diabetes mellitus, cardiovascular or neurovascular disease were selected for the study. The study was approved by the Ethics Committee of Ankara Hospital (Approval no: 3020) in accordance with the regulations of the Ministry of Health. All patients were informed about the study procedures before being included.

\section{Blood Sampling and Biochemical Analysis}

Fasting venous blood samples were obtained from the patients before and after a HD session, while only fasting blood samples were obtained from the CAPD group and controls. Blood samples were drawn into evacuated serum separator tubes containing clot activator (SST Vacutainer ${ }^{\circledR}$, Becton Dickinson). All blood samples were centrifuged at $1500 \mathrm{~g}$ for 10 minutes. Sera were separated and used for routine biochemical testing within two hours. The remaining serum samples were stored at $-80{ }^{\circ} \mathrm{C}$ until the day of analysis for S-100B and NSE assays.

Serum glucose, urea, creatinine (Cre), uric acid (UA), total protein (TP), albumin (Alb), sodium ( $\mathrm{Na}$ ) and potassium (K) levels were measured with original reagent using Olympus AU 2700 analyzer (Mihsima Olympus Co. Ltd. JAPAN).

\section{S-100B and NSE Procedure}

Serum S-100B and NSE measurements were conducted using immunochemistry (Liaison ${ }^{\circledR}$ Sangtec 100, DiaSorin AB Bromma, Sweden). The minimal detection concentration was $0.02 \mathrm{ng} / \mathrm{mL}$ for S-100B and $0.04 \mathrm{ng} / \mathrm{mL}$ for NSE. The intra-assay coefficient of variation (CV) was $3.7 \%$ for S-100B and $0.9 \%$ for NSE. The interassay CVs for S100-B and NSE were 5.7\% and 5.3\%, respectively.

\section{Dialysis Procedure}

All patients underwent HD three times a week for four hours per day, using a synthetic low-flux hollow-fiber filter (polysulfone membrane) (surface area $1.25 \mathrm{~m}^{2}$ ), with an average blood flow rate of $200-300 \mathrm{~mL} / \mathrm{min}$, and a dialysate flow rate of approximately $500 \mathrm{~mL} / \mathrm{min}$ during the HD procedure. For peritoneal dialysis patients, CAPD involved four or five dwells per day of 2-2.5 liters per dwell.

\section{Statistical Analysis}

Descriptive statistics were used to analyze the data. KolmogorovSmirnov test was used for normality testing of the data. Differences between groups were analyzed using the MannWhitney U test. Spearman correlation was used to evaluate the association between variables. Pre- and post-HD values were compared using the Wilcoxon sign test. $\mathrm{P}<0.05$ was considered statistically significant. Statistical analyses were conducted using SPSS version 15.0. 


\section{RESULTS}

Demographic data and biochemical test results are given in Table 1 and Table 2, respectively. Serum S-100B and NSE levels

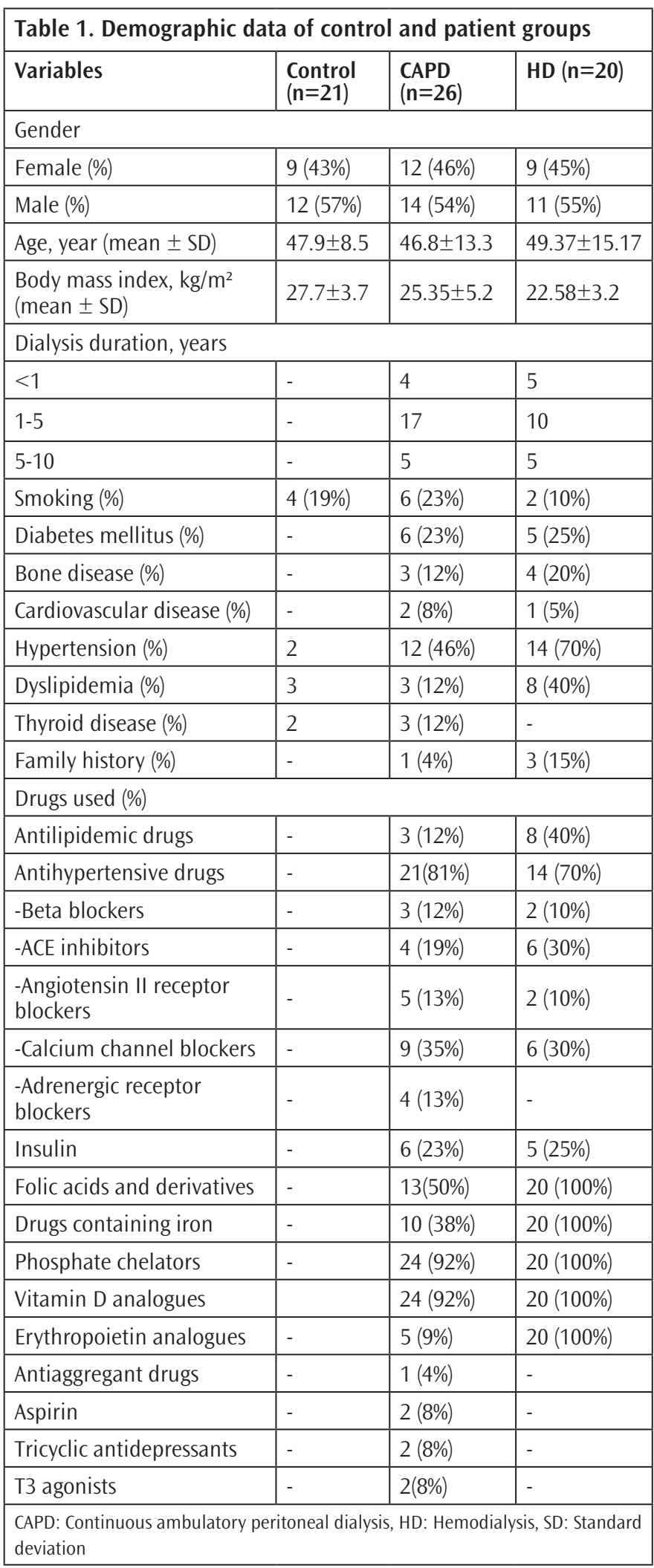

are given in Table 3. Serum S-100B and NSE levels were higher in HD group than in the control group $(p=0.001, p=0.002$, respectively). Serum S-100B and NSE levels were higher in CAPD group than in the control group ( $p=0.002, p=0.009$, respectively). Serum S-100B and NSE levels were significantly diffirent between CAPD and HD groups ( $p=0.023, p<0.001$, respectively) (Table 3). There was a significant positive correlation between S-100B and NSE levels $(r=0.290 ; p=0.006)$. S-100B and NSE levels were also significantly higher following a single HD session $(p<0.001)$ (Table 4). S-100B and NSE results are shown in Figure 1.

\section{DISCUSSION}

The dialysis process may affect several biochemical factors. While many of these changes are beneficial, others can be harmful and increase the severity of the disease.

In the current study, both S-100B and NSE levels were found to be increased in patients undergoing HD and CAPD. When we evaluated the difference between the dialysis types, we found
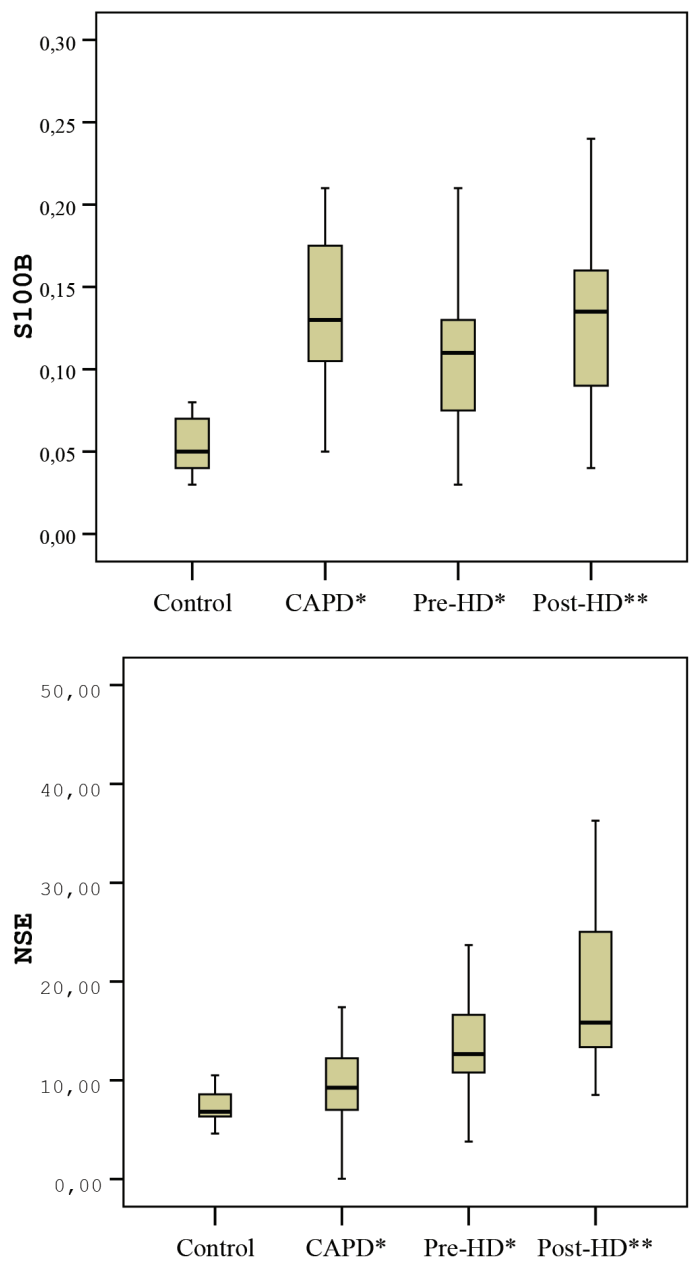

Figure 1. Serum S-100B and NSE levels in the patient and control groups CAPD: Continuous ambulatory peritoneal dialysis, HD: Hemodialysis 
that serum S-100B levels were higher and NSE levels were lower in the CAPD group than in the HD group. The kidneys normally metabolize both S-100B and NSE; therefore, in renal failure, serum levels may be expected to be higher due to decreased renal clearance. Considering the relationship between chronic renal disease and cerebrovascular disorders in these patients, increasing levels of serum S-100B and NSE may be associated with neurological tissue injury.

In this study, we also evaluated the HD effect and found that both serum S-100B and NSE levels were higher in post-HD compared to pre-HD. This could be the result of the hemodilution effect that occurs normally prior to HD and partial hemoconcentration due to dialysis therapy. Another factor contributing to higher levels following HD could be the insufficient permeability of the synthetic hollow-fiber membrane to the S-100B and NSE proteins that could result in ineffective removal. However, there is no study investigating the effect of dialysis on serum S-100B and NSE levels in the literature.
Cerebrovascular diseases are one of the most common reasons for high morbidity and mortality in patients with $\operatorname{ESRD}(1,13)$. The early diagnosis of cerebrovascular disease is important to improve the prognosis and quality of life of these patients. In a previous study, Ikram et al., (14) observed that there was a relationship between decreased GFR levels and the findings in MRI, including cerebral microvascular lesions. Several other studies have reported that decreased GFR is related to an increased prevalence of subclinical lacunar cerebral infarcts detected using MRI $(15,16)$. In another study, decreased GFR was found to be associated with silent cerebral infarcts (17). Kim et al., (18) investigated the association between depression symptoms and serum S-100B concentrations and found that S-100B levels increased in ESRD due to glial pathology and dysfunction of the blood brain barrier. According to these previous studies, we can say that varying degrees of reduction in GFR levels are associated with cerebral pathologies in patients with chronic renal disease. In the diagnosis of cerebrovascular diseases, the measurement of serum S-100B and NSE provides significant advantage since it

\begin{tabular}{|c|c|c|c|c|c|}
\hline Parameters (measuring units) & $\begin{array}{l}\text { Control }(n=21) \\
M(I Q R)\end{array}$ & $\begin{array}{l}\text { CAPD }(n=26) \\
\text { M (IQR) }\end{array}$ & $p^{*}$ & $\begin{array}{l}\mathrm{HD}(\mathrm{n}=20) \\
M(\mathrm{IQR})\end{array}$ & $\mathbf{p}^{*}$ \\
\hline Glucose (mmol/L) & $5.2(1.6)$ & $7.2(4.7)$ & $<0.001$ & $6.9(6.7)$ & $<0.001$ \\
\hline Urea (mmol/L) & $10.6(3.2)$ & $40.2(12.4)$ & $<0.001$ & $46.7(10.2)$ & $<0.001$ \\
\hline Creatinine $(\mu \mathrm{mol} / \mathrm{L})$ & 88 (18) & $778(239)$ & $<0.001$ & $787(265)$ & $<0.001$ \\
\hline Uric Acid (mmol/L) & $0.29(0.06)$ & $0.34(0.07)$ & 0.042 & $0.33(0.06)$ & 0.042 \\
\hline Total protein $(\mathrm{g} / \mathrm{L})$ & $69(5)$ & $67(9)$ & 0.062 & $68(6)$ & 0.070 \\
\hline Albumin $(\mathrm{g} / \mathrm{L})$ & $42(4)$ & $37(4)$ & 0.001 & $36(4)$ & 0.001 \\
\hline $\mathrm{Na}(\mathrm{mmol} / \mathrm{L})$ & $139.3(2.5)$ & $138.6(3.4)$ & 0.125 & $136.0(5.0)$ & 0.102 \\
\hline $\mathrm{K}(\mathrm{mmol} / \mathrm{L})$ & $4.4(0.4)$ & $4.3(0.5)$ & 0.086 & $5.4(0.8)$ & 0.001 \\
\hline Systolic blood pressure (mmHg) & $115(12)$ & $132(19)$ & 0.001 & $142(19)$ & 0.001 \\
\hline Diastolic blood pressure $(\mathrm{mmHg})$ & $75(6)$ & $82(9)$ & 0.001 & $80(11)$ & 0.001 \\
\hline
\end{tabular}

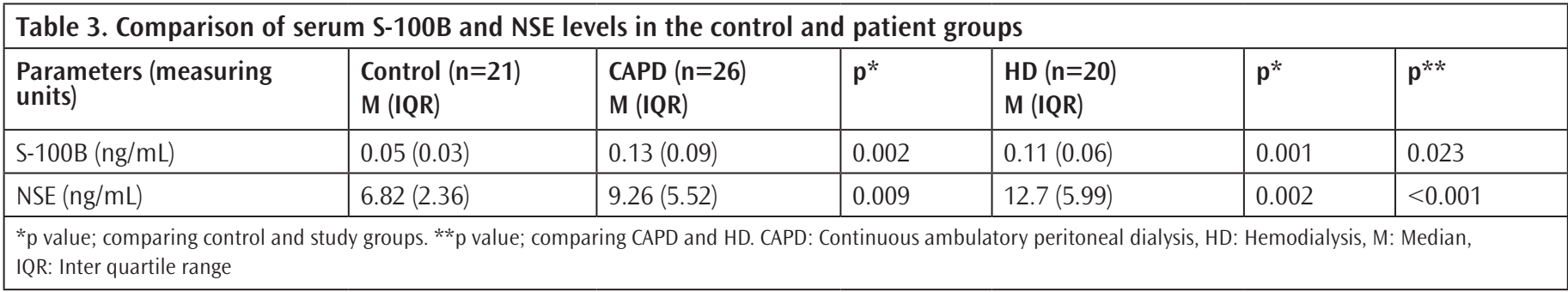

\begin{tabular}{|l|l|l|l|}
\hline \multicolumn{4}{|l|}{ Table 4. Comparison of serum S-100B and NSE levels before and after hemodialysis } \\
\hline Parameters (measuring units) & Before $(\mathbf{n}=\mathbf{2 0}) \mathbf{M}(\mathrm{IQR})$ & After $(\mathbf{n}=\mathbf{2 0}) \mathbf{M}(\mathrm{IQR})$ & $\mathbf{p}^{*}$ \\
\hline S-100B $(\mathrm{ng} / \mathrm{mL})$ & $0.11(0.06)$ & $0.13(0.07)$ & $<0.001$ \\
\hline NSE $(\mathrm{ng} / \mathrm{mL})$ & $12.7(5.99)$ & $15.84(11.72)$ & $<0.001$ \\
\hline${ }^{*} \mathrm{p}$ value; comparing before and after hemodialysis, M: Median, IQR: Inter quartile range & \\
\hline
\end{tabular}


is easy to perform and non-invasive; however, there is no study in literature investigating S-100B and NSE concentrations in patients with ESRD, and the present study is the first in this field.

\section{CONCLUSION}

In this study, we determined that serum S-100B and NSE levels increased in patients undergoing HD and CAPD therapy compared to controls. Therefore, these markers might be valuable in determining the possible risk of a cerebrovascular event in patients with chronic renal disease. Nevertheless, one of the limitations of this study was that further studies are needed to compare serum S-100B and NSE levels with MRI findings in patients with CRF. Another limitation was that study cohort was relatively small.

\section{Ethics}

Ethics Committee Approval: The study was approved by the Ethics Committee of Ankara Hospital (approval no: 3020) in accordance with the regulations of the Ministry of Health.

Informed Consent: All patients were informed about the study procedures before being included.

Peer-review: Externally peer-reviewed.

\section{Authorship Contributions}

Surgical and Medical Practices: M.S., A.A., M.D., D.Y., Concept: M.A., O.Ö., M.Ş., D.Y., Design: M.A., O.Ö., M.Ş., Data Collection or Processing: M.A., O.Ö., M.F.A., M.S., Analysis or Interpretation: M.A., D.Y., Literature Search: M.A., O.Ö., M.F.A., Writing: M.A., O.Ö., D.Y.

Conflict of Interest: No conflict of interest was declared by the authors.

Financial Disclosure: The authors declared that this study received no financial support.

\section{REFERENCES}

1. Kunihara T, Shiiya N, Bin L, Yasuda K. Arterio-jugular differences in serum S-100 beta proteins in patients receiving selective cerebral perfusion. Surg Today 2006;36:6-11.

2. Herrmann M, Ebert AD, Galazky I, Wunderlich MT, Kunz WS, Holzmann D. Neurobehavioral outcome prediction after cardiac surgery: role of neurobiochemical markers of damage to neuronal and glial brain tissue. Stroke 2000;31:645-50.
3. Mielck F, Ziarkowski A, Hanekop G, Armstrong VW, Hilgers R, Weyland A, et al. Cerebral inflammatory response during and after cardiac surgery. Eur J Anaesthesiol 2005;22:347-52.

4. Infante JR, Martinez A, Ochoa J, Cañadillas F, Torres-Avisbal M, Vallejo JA, et al. Cerebrospinalfluid S-100 protein levels in neurological pathologies. J Physiol Biochem 2003;59:255-61.

5. Heizmann CW, Fritz G, Schafer BW. S100 proteins: structure, functions and pathology. Front Biosci 2002;7:1356-68.

6. Jonsson $\mathrm{H}$, Johnsson P, Alling C, Westaby S, Blomquist S. Significance of serum S100 release after coronary artery bypass grafting. Ann Thorac Surg 1998;65:1639-44.

7. Rothoerl RD, Brawanski A, Woertgen C. S-100B protein serum levels after controlled cortical impact injury in the rat. Acta Neurochir (Wien) 2000;142:199-203.

8. Kilminster S, Treasure T, McMillan T, Holt DW. Neuropsychological change and S-100 protein release in 130 unselected patients undergoing cardiac surgery. Stroke 1999;30:1869-74.

9. Steinberg R, Gueniau C, Scarna H, Keller A, Worcel M, Pujol JF. Experimental brain ischemia: Neuron-specific enolase level in cerebrospinal fluid as an index of neuronal damage. J Neurochem 1984;43:19-24.

10. Schoerkhuber W, Kittler H, Sterz F, Behringer W, Holzer M, Frossard M, et al Time course of serum neuron-specific enolase. A predictor of neurological outcome in patients resuscitated from cardiac arrest. Stroke 1999;30:1598603.

11. Herrmann M, Ebert AD, Tober D, Hann J, Huth C. A contrastive analysis of release patterns of biochemical markers of brain damage after coronary artery bypass grafting and valve replacement and their association with the neurobehavioral outcome after cardiac surgery. Eur J Cardiothorac Surg 1999;16:513-8.

12. Toyoda K. Cerebral Small Vessel Disease and Chronic Kidney Disease. J Stroke 2015;17:31-7.

13. Raskin NH. Neurologicalcomplications of renalfailure. In: Amino MJ, ed Neurology and general medicine, $2^{\text {nd }}$ ed. New York: Churchill Livingstone 1995;311-3.

14. Ikram MA, Vernooij MW, Hofman A, Niessen W], van der Lugt A, Breteler MM. Kidney function is related to cerebral small vessel disease. Stroke 2008;39:55-61.

15. Seliger SL, Longstreth WT, Katz R, Manolio T, Fried LF, Shlipak M, et al. Cystatin C and subclinical brain infarction. J Am Soc Nephrol 2005;16:3721-

16. Kobayashi S, Ikeda T, Moriya H, Ohtake T, Kumagai H. Asymptomatic cerebral lacunae in patients with chronic kidney disease. Am J Kidney Dis 2004:44:35-41.

17. Kobayashi M, Hirawa N, Yatsu K, Kobayashi Y, Yamamoto Y, Saka S, et al. Relationship between silent brain infarction and chronic kidney disease. Nephrol Dial Transplant 2009;24:201-7.

18. Kim JW, Kim SG, Kim HJ, Song YR. Serum S-100B protein is associated with depressive symptoms in patients with end-stage renal disease. Clin Biochem 2012;45:1573-7. 